Talía. Revista de estudios teatrales

ISSN-e: 2659-806X

http://dx.doi.org/10.5209/TRET.63224

\title{
Los espacios teatrales y la crisis del 2008: Resistencia, reconstrucción y nuevos territorios
}

Carole Viñals*

Recibido: 26 de abril de 2018 / Aceptado: 27 de diciembre de 2018

Resumen. Este trabajo esboza un panorama del teatro independiente español surgido después de la crisis del 2008. Este teatro se relaciona con el de los años sesenta, pero mantiene diferencias con un enfoque más subjetivo. También nos interesamos por el teatro de habla hispana en el extranjero que crea nuevos lazos transnacionales forjando identidades.

Palabras clave: Teatro de la crisis, Teatro de la emigración, Teatro comprometido

The theatrical spaces and the crisis of 2008: Resistance, reconstruction and new territories

\begin{abstract}
This work outlines a panorama of Spanish independent theater emerged after the crisis of 2008. This theater is related to that of the sixties, but maintains differences with a more subjective approach. We are also interested in Spanish-language theater abroad that creates new transnational ties
\end{abstract} forging identities.

Keywords: Theater of crisis, Theater of emigration, Committed theater

Cómo citar: Viñals, C. (2019). Los espacios teatrales y la crisis del 2008: Resistencia, reconstrucción y nuevos territorios, en Talía. Revista de estudios teatrales, 1, 213-224.

\section{Introducción}

El teatro independiente es un "teatro libre, que rechaza cualquier tipo de censura y que se lo debe todo a sí mismo" [Los Goliardos 1969: 12]. Supone autores "que se interesan por problemas de nuestro tiempo. Los que se comprometen con lo que ven. Los que no están conformes. Los que quieren cambiar algo" [Los Goliardos 1969: 10]. El Manifiesto publicado por los autores de teatro independiente en Primer Acto en 1969 vuelve a cobrar hoy en día actualidad. La fe en el sistema se ha visto puesta a prueba con la crisis del 2008, mientras la concienciación política de los ciudadanos se iba extendiendo a las artes teatrales, reactivando tendencias escénicas ya presentes en la cultura de tradición socialista. Algunos espacios escénicos se han convertido en lugares de resistencia contra la hegemonía ideológica y cultural. Hoy asistimos,

* Universidad de Lille. 
pues, a un renacer de un teatro social, pero con otras formas de compromiso tras la lenta agonía de la utopía comunista.

Mas, si bien es cierto que se construyen colectivos teatrales formando comunidades locales que hacen hincapié en la cercanía, también notamos conexiones entre los distintos grupos así como lazos internacionales. Lo más cercano y lo más lejano se funden. El mundo ha cambiado respecto a los años sesenta. En este trabajo se tratará pues a la vez de hacer hincapié en las semejanzas y de mostrar las diferencias.

Veremos primero cómo estos colectivos se centran en los perdedores de la crisis, con un sentimiento de indignación, muchas veces enjuiciando al sistema. Luego mostraremos cómo este teatro propone otro tipo de espacio donde el compromiso adopta un enfoque subjetivo, lo que lo distingue del teatro social anterior, antes de interesarnos por los nuevos grupos teatrales de habla hispana que han surgido, por ejemplo en Berlín, forjando identidades transnacionales.

\section{Un teatro ciudadano que enjuicia al sistema}

Los casos de corrupción han inspirado a dramaturgos como Jordi Casanovas con obras como Ruz-Bárcenas, basada en las declaraciones del ex-tesorero del PP ante su juez en la Audiencia Nacional el 15 de julio de 2013. La obra, dirigida por Alberto San Juan, se estrenó en mayo del 2014 en Madrid, y luego se representó en el Teatro Lliure en diciembre. La crisis económica ha provocado una grave crisis de conciencia. El propio sistema y sus fallos aparecen como responsables de la situación. Se enjuicia tanto al capitalismo y a sus desenfrenos como a la corrupción a todos los niveles. Esta última, que antes movía a risa, ha dejado de hacer sonreír y la gravedad ha reemplazado el humor. En este teatro surgido de la indignación desatada por la crisis que reactiva formas antiguas de teatro social, el espacio escénico se transforma pues en sala de juicio. El escritor Raúl Quirós es, por ejemplo, autor de The Dinner, una obra acerca de la corrupción en España que se representó en Londres el 25 de febrero de 2015: aparecen en ella un inversor inmobiliario y un magnate de los casinos.

El sentimiento general en España tras el estallido de la crisis y los escándalos ligados a la corrupción es la indignación frente a la irresponsabilidad de los políticos. Cero responsables es un ejemplo de ello. La representación en 2010 de la catástrofe del metro de Valencia, acaecida en 2006 y que se había llevado la vida de 43 personas causando 47 heridos, pretendía apoyar a la Asociación de Víctimas del metro 3 de julio reflexionando sobre los conceptos de responsabilidad y de irresponsabilidad [Sirera 2010]. Se trata de difundir información por otros canales con un discurso crítico. “¿Cuál es la capacidad de difusión de otras ideas? Los canales masivos de información están absolutamente bajo control con lo cual, la libertad de expresión es muy relativa", afirmaba entonces Sirera [2010]. En este contexto el teatro es desalienante. Uno de los esloganes del 15M era "No nos representan". En el caso de este nuevo teatro, asistimos al intento de superar el problema de la representatividad de las élites. La sociedad entera aparece, pero a contra-corriente. No solo se trata de enjuiciar al sistema, también se recuerdan sus fallos y sus olvidos culpables.

No solo se critica la corrupción y la política española, sino también el propio capitalismo. En Masacre, una breve historia del capitalismo español que él mismo interpretó en Lavapiés en 2017 junto a Marta Calvó, San Juan opone capitalismo y libertad inspirándose en el ensayo de Naomi Klein La Stratégie du Choc [2007]. El 
teatro se opone al capitalismo como espacio de resistencia. Con sus modalidades propias, este teatro inventa un espacio de producción, pero también de intercambios libres de las leyes del mercado, representando así formas económicas alternativas. De hecho, este teatro independiente se acompaña de formas de consumo que pretenden superar el consumismo obsesivo de buena parte de la sociedad española desde el final de la Transición. El Teatro del Barrio, por ejemplo, ha adoptado la forma de cooperativa de consumo cultural. El objetivo es crear una comunidad de socios activos con la participación colectiva en el debate crítico, en las labores de la gestión interna, o en la búsqueda de fuentes de financiación. El Teatro del Barrio también pone en valor una poderosa herramienta en manos de la ciudadanía: el consumo responsable. Este teatro quiere participar del nacimiento de una nueva economía, una economía creada desde abajo por el consumidor consciente.

Estas obras critican el sistema proponiendo otros modelos de creación. Estamos ante creaciones colectivas que comprometen al público en su rol social. El espectador se enfrenta a la opresión y se convierte en espect-actor, abandonando la pasividad y buscando soluciones para mejorar la sociedad. Cero responsables fue escrita de forma colectiva lo cual entronca con una práctica frecuente en los años sesenta:

la creación colectiva pretende esencialmente romper en el ámbito estrictamente creativo la división del trabajo teatral imperante [...] esta división corresponde, en última instancia, a la división del trabajo en el modo de producción capitalista, de suerte que todo intento de destruir la primera constituye de algún modo una impugnación del sistema capitalista en la esfera específica del teatro [López Mozo 1976: 28].

En estas obras el teatro "se transforma en intrumento de la formación de un pensamiento político" [Weiss 1968: 11]. La escritura colectiva implica "una supresión de jerarquías que pone fin a la dictadura del director dentro del grupo. La discusión, pues, se hace más rica, más abierta, en cuanto que en ella participan todos los miembros en un plano de igualdad " [López Mozo 1976: 32]. Se trata de despertar las conciencias: "Lo más a que se puede aspirar en el plano político es a despertar la conciencia de las gentes. Si ello se consigue, el teatro habrá cumplido su función, porque a partir de entonces otros serán los medios de que se han de servir para cumplir sus aspiraciones" [Weiss 1968: 11]. Este teatro nos recuerda que la responsabilidad es colectiva y que todos, no solo los políticos, muy identificados últimamente con la corrupción, podemos reflexionar y proponer soluciones. El dispositivo escénico va encaminado a que el espectador se convierta en actor:

Los participantes que intervengan tienen obligatoriamente que continuar las acciones físicas de los actores que son sustituidos; no se les permite que, simplemente, entren en escena y se pongan a hablar y hablar y hablar: tienen que continuar el mismo trabajo o las mismas actividades de los actores que estaban en su lugar. La actividad teatral debe seguir igual, en escena [Boal 2009: 43].

Los espectadores se ven obligados a actuar, a poner en práctica sus propuestas: no se trata solo de teorizar sino de enfrentarse a la realidad. Hay en este teatro una voluntad de oponerse al sistema, de proponer otra soluciones, de situar al ciudadano en el centro del dispositivo social, para politizarlo y empoderarlo. 
Uno puede proponer cualquier solución, pero en escena, trabajando, actuando, haciendo cosas, y no desde la comodidad de su butaca. Muchas veces, uno es muy revolucionario cuando en un foro pronostica y sugiere actos revolucionarios y heroicos; en cambio a menudo advierte que las cosas no son tan fáciles cuando tiene él mismo que practicar lo que sugiere [Boal 2009: 43].

En estos espacios teatrales, el concepto de espacio público proletario se opone al espacio público burgués. Recuperan una tradición que tuvo lugar en las plazas y en las calles. En los años sesenta, las salas solían ser naves de cualquier tipo, salones de colegios...

podría citar los casos del TEI cuyo local de la calle Magallanes es lo menos parecido a un teatro, pues consiste en una pequeña sala rectangular sin escenario ni butacas fijas ; el Lebrijano, que ha actuado en un viejo gimnasio abandonado, situado a las espaldas de un cine en la plaza de Roma, en Madrid ; y el TU de Murcia, que gestiona actualmente la utilización de uno de los pabellones de la Feria Internacional de la Conserva y la Alimentación [López Mozo 1976: 87].

La calle, las plazas, las casas, los lugares de convivencia y conflicto, ponen de manifiesto la relación entre arquitectura y espacio político, esto es, espacios agonistas [Arendt 2000]. El espacio público proletario hace que se desmorone el espacio publico burgués y sus pretensiones generalizadoras:

el rechazo del escenario a la italiana no es, sin embargo, una cuestión de tipo exclusivamente técnico. Su existencia y la del edificio teatral que le contiene, guarda estrecha relación con el amplio movimiento social que llevó a la burguesía a la cúspide del poder y la permitió dictar normas por las que se arrogó el derecho a controlar los medios de producción culturales y a convertirse en la única destinataria del hecho teatral [López Mozo 1976: 96].

La arquitectura del teatro de barrio y del teatro campesino se caracterizaba por ser temporal y de carácter efímero. Los objetivos implicaban la elaboración de un "contra-espacio" público. Se busca otros espacios, no institucionales, donde las pautas regladas del espacio escénico se puedan cuestionar, para ensayar otras propuestas teatrales y otra relación con el público, espacios populares tanto en las ciudades como en ámbitos rurales. El advenimiento de la burguesía se acompañó del advenimiento de la ruptura radical entre estas dos esferas.

Se trata también de despertar el interés hacia el teatro de un público alejado de él. El público no pertenece a la burguesía. El nuevo espacio escénico es pues otra forma de protesta que va contra el concepto burgués del papel pasivo del espectador en el teatro. "El teatro se ha des-definido" [Dubatti 2007: 74]. Esta des-construcción del teatro conlleva también una nueva construcción, la de otro espacio teatral que se relaciona con el mundo del trabajo, las cárceles... Lo exterior se ve así incorporado en el interior.

Teatro de Barrio, Teatro de los Oprimidos, Teatro del Compromiso: frente a la crisis, este teatro reactiva opciones críticas hacia el sistema que parecían olvidadas. Pero el compromiso de estas compañías se distingue sobre todo del teatro anterior por el papel desempeñado por la subjetividad y la figura del testigo. 


\section{Nuevas espacialidades: subjetividad y figura del testigo}

La misma raíz latina, con un significado jurídico, se encuentra en las palabras "protestación" y "contestación": testis (testigo). El punto de vista de una persona que da su visión es pues central. En los escenarios también estamos en la "era del testigo" [Wieviorka 1998]. De hecho, el primer significado de la palabra latina contestatio es judicial: es un llamamiento a otro testimonio, o el rechazo de una palabra falsa. Protesta y contestación se caracterizan pues por la idea de refutar, dudar de la veracidad de un testimonio, proponiendo otra versión subjetiva. Con la creación del Teatro de barrio, se pretende dar voz a los olvidados de la Transición del 78 apoyándose en los testimonios:

Los escritores tenemos la responsabilidad de contestar a ese status quo y plantear qué significa hoy el franquismo y la memoria histórica, por qué es un problema político que haya más de 100.000 desaparecidos y por qué aquí no se hace nada. Al menos, tenemos la obligación de hacer esas preguntas [Quirós 2015].

Junto al Teatro de Barrio, cabe mencionar el Teatro de los Oprimidos de Barcelona. La opresión también puede ser el uso de la violencia para demostrar la autoridad, los actos de tiranía, y es un término que suele asociarse a los gobiernos. Se inspira de la Pedagogía de los Oprimidos de Paulo Freire. Así se autodefinen los fundadores del Teatro por la memoria en el 2013:

No se trata de una asociación cultural, ni de un movimiento: no tenemos un manifiesto, ni un programa, ni siquiera tenemos socios. No somos nada: palabras. Somos una idea compartida: la de que el teatro debe clamar, desde las tablas, desde los cuerpos y las voces de los actores, desde el texto dramático, la urgente necesidad de que los derechos de nuestros ciudadanos sean restablecidos [Quirós 2015].

Se trata para este pequeño teatro autogestionado de recordar el pasado, la memoria de los desaparecidos de la dictadura. En el teatro fórum [Boal 2009: 117], cada persona oprimida cuenta su historia particular ante un público que se identifica con la situación narrada. El caso es que, para resistir al sistema, la memoria personal y colectiva son el mejor instrumento. El modelo del Teatro del Compromiso es el teatro argentino: el Teatro $x$ la identidad apoya desde el año 2000 a las Abuelas de Plaza de Mayo. La historia traumática de cada persona deja así de ser única o estrictamente personal para convertirse en un testimonio que revela en el ritual del teatro todo su poder al ser acogido por la comunidad como parte sustancial de una indestructible memoria colectiva.

Centrarse en la humanidad más humilde implica otra relación con la espacialidad. Son compañías a escala reducida pero que sin embargo logran integrar en su interior al mundo. El Calder Bookshop Theatre es una sala diminuta en los bajos de una librería. Apelaciones como " teatro del barrio" remiten a "la escala reducida a la dimensión de lo corporal, la pequeña comunidad, lo tribal, lo localizado" [Dubatti 2007: 92]. En semejante contexto, los medios y locales utilizados son primitivos y rudimentarios. Cada uno (actor, autor, espectador) participa de este teatro en el que se teje una comunidad. Estamos ante un teatro terrenal, perecedero. Hecho con pocos medios y publicidad escasa. La mayoría de los actores son casi anónimos, alejados 
de las grandes maquinarias industriales de los medios. Estamos en un espacio diminuto y efímero:

En el convivio no sólo resplandece el aura de los actores: también la del público y los técnicos. Reunión de auras, el convivio teatral extiende el concepto benjaminiano. El encuentro de auras no es perdurable, dura lo que el convivio: en consecuencia, es también imperio de lo efímero, de una experiencia que sucede e inmediatamente se desvanece y se torna irrecuperable [2007: 33].

En Filosofía del Teatro I, se destaca el valor particular del convivio como una característica central del teatro y de un arte no reproductible. El convivio se arraiga en lo humano: es la unión de artistas, técnicos y espectadores que conforman un presente único, breve e imposible de reproducir. Cada función es única, cada presente es excepcional. El teatro es obra de arte, magia y no objeto de consumo reproducible mecánicamente. En nuestra era tecnológica el teatro es lo más humano. Este teatro es por naturaleza empírico, y cambiante.

El teatro es un lenguaje ancestral, que remite a una antigua medida del hombre: la escala reducida a la dimensión de lo corporal, la pequeña comunidad, lo tribal, lo localizado. Porque el punto de partida del teatro es el encuentro de presencias, el convivio o reunión social [2007: 34].

De hecho, este teatro pretende también construir nuevos lazos de convivencia. La primera persona del plural plasma esta representación colectiva del grupo. En nuestra sociedad líquida donde los lazos familiares y de cercanía se han ido rompiendo, este teatro pretende reconstruir rehumanizando. "Hay una relación entre la idea de democracia y un determinado tipo de práctica artística que dedica su mirada a los individuos comunes y corrientes, a su cotidianeidad, que es la cotidianeidad de todos" [Viñals 2015: 67]. Muchas de las pancartas de la Puerta del Sol criticaban la falsedad de la democracia. Estos grupos teatrales pretenden realizar en escena una democracia real en la que todos sean escuchados. La palabra ha de pertenecer a todos. Y cada uno tiene derecho a opinar. En el Teatro del Barrio (una sala situada en el barrio madrileño de Lavapiés) abundan los ejemplos: el juicio a Garzón ha sido objeto de una puesta en escena titulada El pan y la sal (2015) que se basa en testimonios. Se trata de teatro documental en el que se reproducen los intercambios entre Baltasar Garzón Real, su abogado Gonzalo Martínez Fresneda, y el juez Carlos Granados Pérez, magistrado jefe del Tribunal Supremo. Pero sobre todo aparecen los supervivientes María Martín López, de 81 años y Pino Sosa de 75 años. El título de la obra está sacado de las declaraciones de un testigo: «Cuando se llevaron a mi padre yo era muy pequeñina. Se nos llevaron el pan y la sal de nuestras casas, porque mi madre quedó enferma, buscaba a mi padre y nunca lo encontró». Lo político y lo social aparecen a través de estas figuras de los testigos, cuya subjetividad propone una visión singular de la Historia colectiva. Lo humano y la corporeidad cobran una importancia esencial a través de estas figuras que remiten a la microhistoria. Esta figura testimonial aparece sobre todo en las representaciones con temática memorialista. El tema de las fosas ha sido tratado por Mercedes Herrero Pérez en Exhumación, materia cruda en 2013: la compañía Pez Luna teatro puso en escena testimonios de las cuatro actrices Milagros Martín, Goya Bravo, Julia Merino y Carmina Alonso (cuatro octogenarias 
que eran niñas de un año, tres, cuatro y cinco cuando asistieron a la detención de sus padres) acompañadas por el arqueólogo Julio del Olmo. A través de la plataforma datos.desmemoriados.org se subían fotografías, documentos y también entrevistas con diferentes testimonios que se están recogiendo. También ha sido tratado el tema por Juana Escabias, en Cautivas (2015), una obra basada en Testimonios de mujeres en las cárceles franquistas de Tomasa Cuevas (2004).

Se trata pues de reconectar con la realidad perdida. Este teatro constituye incluso una crítica implícita a la deshumanización de una sociedad que Zigmunt Bauman ha llamado "líquida" [1999] por carecer de raíces. El teatro se convierte en un parapeto que sostiene una comunidad deshecha [Nancy 1986: 25]. Una comunidad en el sentido de Yudice, es decir "un ensemble existant de relations, impliquant une connexion- comme la parenté, l'héritage culturel, les valeur et les buts partagés" [en Pavis 2014: 48]. En estos grupos el teatro es "el encuentro de presencias, el convivio o reunión social" [2007: 92]. El convivio es pues la base de la teatralidad, un lugar donde "producir la comunidad" [Mondzain 2002: 129]. El teatro de barrio implica "una práctica de socialización de cuerpos presentes, de afectación comunitaria, y significa una actitud negativa ante la desterritorialización sociocomunicacional propiciada por las intermediaciones técnicas" [García Canclini 1995: 18]. Asistimos a "la proximidad del encuentro de los cuerpos en una encrucijada geográfico-temporal, emisor y receptor frente a frente o "modalidad de acabado" [Muschietti 1986: 27].

Lo hemos dicho: vivimos una época de crisis y de caos, a todos los niveles. Crisis económica, crisis política, crisis cultural: los modelos vacilan y alteran nuestra relación con la realidad. Todo está en movimiento. El individuo experimenta inseguridad material (el paro se generaliza y el trabajo escasea), y las identidades colectivas también se tambalean. El individuo se encuentra perdido, desnortado material y físicamente. Teme por su seguridad, su identidad. En semejante contexto, el teatro tiene un fin de reafirmación, de búsqueda de sí mismo en un mundo cada vez más complejo e inasible. El espacio de este nuevo teatro será la pequeña escala (el barrio). La pequeña escala permite volver a tejer lazos y comunidades. Dar confianza. Se multiplican los centros, contrarrestando el movimiento de recentralización global:

El teatro parece un lenguaje especialmente diseñado para resistir la mundialización imaginada por la nueva derecha y la expansión capitalista. El teatro es complementario con la utopía de la izquierda de un "mundo multipolar" y policéntrico, un "mundo regionalizado", donde paradójicamente lo que se mundialice sea la multipolaridad. [Dubatti 2007: 48].

Pese a su apelación, "barrio", que parece restringir su campo a un espacio determinado y cerrado, sucede todo lo contrario, ya que el teatro de barrio se expande y estas compañías nacidas en los barrios, no solo hacen giras más alla de los límites acotados de la vecindad sino que se expanden en la medida en que aquellos que fueron espectadores suelen convertirse en actores o creadores de otros grupos. El teatro de barrio tiene pues una dimensión universal.

Mas la crisis se ha acompañado de otro fenómeno: la emigración económica de muchos jóvenes. Esta generación del 15M se caracteriza por su juventud y su alto nivel de estudios. Estos emigrantes van a crear, pues, fuera de las fronteras españolas, otras formas teatrales que combinan preservación de su identidad y cosmopolitismo. 


\section{La generación del $15 \mathrm{M}$ en las tablas: borrando fronteras}

En la capital alemana, desde la crisis del 2008 y hasta hace pocos años, cuando empezaron los regresos, han florecido multitud de propuestas teatrales en castellano. Estas últimas son muy variadas y a veces originales. La presencia del teatro de habla hispana es particularmente notable en una capital alemana que cuenta con una comunidad hispánica muy importante. Este fenómeno del teatro en español en Berlín no es reciente, aunque se haya extendido mucho últimamente debido a la crisis. Desde 1992, el colectivo hispano-alemán Tallercito mantiene una tertulia literarioteatral semanal y, al ritmo de dos o tres estrenos anuales, realiza también proyectos de teatro independiente en español. El nombre Tallercito sugiere modestia. Un taller es un lugar donde se trabaja. Remite a la cultura obrera, a algo que está haciéndose y que no está acabado del todo. El diminutivo contribuye a dar la sensación de que nos encontramos frente a un proyecto modesto, de dimensiones reducidas. El espacio de encuentro del Tallercito son los locales del sindicato FAU en la Lottumstraße 11, Berlín-Prenzlauer Berg. Los lazos cultura, mundo obrero y sindicato aparecen a través de la naturaleza del local. Las escenificaciones de este teatro independiente fuera de las fronteras nacionales se muestran en salas alternativas de la ciudad. La tertulia comparte textos, de vanguardia o clásicos, los debate y anima su puesta en escena. Puede tratarse de teatro, de baile, de lectura de textos... Lo importante es la dimensión social y crítica. Es un teatro consciente de su tiempo.

Este teatro alternativo suele ser un teatro de denuncia feminista, social, política... Algunos colectivos combinan varias tendencias. Estas compañías, modestas en sus ambiciones e independientes de los poderes oficiales, tal vez por el hecho de ser geográficamente excéntricas, tal vez por proceder de la sociedad civil, están generalmente dirigidas por mujeres, lo cual contrasta con el ámbito teatral institucional, que suele ser más masculino, por lo menos en lo referente a los altos cargos directivos. Estos colectivos no se benefician de ayudas estatales y permacecen marginados, razón por la cual contribuyen a su manera no institucional al mantenimiento de una cultura hispánica viva y demuestran una creatividad y una capacidad de adaptación a veces superior a la de otras compañías. Estamos ante un teatro de resistencia cultural que se sitúa sobre todo en la contra-cultura más que en la cultura de protesta aunque esta última influencia no se pueda descartar en algunos casos. Este teatro se empeña en construir a contracorriente un territorio cultural sincrético habitando una nueva espacialidad.

La emigración pone en peligro la identidad y la transmisión lingüística y cultural. No es pues de extrañar que los grupos teatrales berlineses dirigidos por hispanohablantes representen obras basadas en cuentos. El cuento teje lazos entre los inmigrantes, reconstruyendo una unidad perdida. Como lo subrayó Benjamin "aquel que escucha una historia, forma sociedad con aquel que la cuenta" [Nières-Chevrel 2009: 75]. Los emigrantes económicos vuelven de esta forma a tejer lazos culturales entre sí. La finalidad de este teatro puede consistir en preservar un idioma, una cultura, una identidad.

El Kazibaze es otro ejemplo de ello: se trata de una compañía berlinesa fundada en el 2011 por dos españolas de Barcelona, las actrices Marina Rodríguez y Clara Gracia. Presentan obras infantiles como Zwei Omas und ein Buch (con títeres) y Alguien se ha colado en mi burbuja (un solo de danza-teatro interpretado por Clara Gracia en 2012 e inspirado en La campana de cristal de Sylvia Plath). 
La Cueva se especializa en cuentos en alemán y cubano. Sus cuentos parten de los hermanos Grimm, que fueron recopiladores de la cultura popular. El grupo La Cueva representó por ejemplo en versión bilingüe Caperucita Roja en noviembre 2012, así como historias de los dioses afrocubanos. La tradición oral y popular es importante en este grupo multicultural con actrices venidas de Cuba, Alemania o Argentina. Varios continentes, varias culturas, varios imaginarios pero tres mujeres: María Magdalena González (una cubana) Marlene Margarette -Lux (una alemana) y Nahuel Bon (una argentina).

El colectivo Mosaico, fundado en el 2015, también produce obras infantiles y piezas para adultos en distintos espacios de Berlín. En el grupo participan Daniela Zaror, Estelle Sollem, Gonzalo, Helga Delgado e Israel Valente. Un mosaico es una figura constituida por distintas piezas de diversas procedencias y que, juntas, forman un dibujo común. La palabra "Mosaico" remite a mezcla, melting pot, diversidad y armonía. Los nombres de estos colectivos contienen pues una símbología muy rica.

La representación teatral va a remendar pues los desgarros. Estas nuevas propuestas apuntan también hacia una nueva espacialidad: abarcan otros territorios a la vez que preservan el patrimonio cultural hispánico. Todo cuanto hemos apuntado se acompaña de la creación de nuevos lazos entre comunidades a veces opuestas. Los Otros (todos los otros) tienen cabida en estos espacios teatrales reducidos. Es el caso de los grupos teatrales altrenativos en el extranjero. Protegen su propia lengua y su identidad hispánica y a la vez acogen nuevas culturas, siendo acogidos por ellas.

La propuesta del colectivo Theater am Tisch, un teatro democrático que nace en Italia en 2010 y se crea en Berlín en 2012, consiste en que las representaciones se llevan a cabo en diferentes bares. Es otra forma de hacer teatro transformándolo en un producto a la carta, de forma lúdica. Una de sus obras, Altbau, trataba de las relaciones entre berlineses y extranjeros en un edificio antiguo de Berlín. Theater am Tisch es interesante: los comensales de un café o restaurante, reciben dos menús: la carta normal para la comida y las bebidas y un menú con una selección de monólogos y diálogos en distintos idiomas (por supuesto hay piezas en español). La mezcla de idiomas sugiere apertura al Otro y la carta permite al espectador escoger tanto la lengua como el texto. Es una forma de desmitificar el arte, volviéndolo asequible como un menú y recordando también la importancia de la cultura, tan necesaria como el alimento.

La lengua no parece se un obstáculo para estas formas de teatro ectópico:

“Literatura ectópica”es una expresión que puede ser utilizada para denominar la literatura que ha sido escrita por autores que se han desplazado de su lugar de origen a otro lugar, implicando ese desplazamiento en muchos casos inmersión en una realidad lingüística distinta de la de origen e incluso cambio de lengua [Albaladejo 2011: 143].

Este concepto de "ectópico" también puede aplicarse al teatro representado fuera de las fronteras. La comunicación con el Otro, todos los Otros se ve así facilitada. Estos colectivos de habla hispana en Berlín están "fuera del que sería su topos propio y se sitúa en otro topos, que también es lugar, espacio, pero distinto del previsible" [Albaladejo 2011: 143]. Crean sus propias obras, la mayoría fábulas sin espacio real. Estas obras encuentran otro territorio, "en relación con el topos primero, el habitual" [Albaladejo 2011: 143]. El territorio es aquí el espacio escénico: debe ser entendido desde la 
noción de lugar antropológico propuesta por Augé como aquél que "no es sino la idea, parcialmente materializada, que se hacen aquellos que lo habitan de su relación con el territorio, con sus semejantes y con los otros" [Augé 2000: 56]. La escena deviene un lugar de diálogo entre inmigrantes donde se preserva la identidad perdida a la vez que se fraguan nuevas identidades. Para salvar al Otro y a nosotros mismos.

En cuanto al grupo Calaca, presentan obras como Invisibles - Menschen ohne Papiere en 2012. Se trata de teatro callejero que representa a los invisibles, los indocumentados, aquellos que por situarse fuera del espacio Schengen no encuentran su lugar. Estamos ante grupos que abogan por una espacialidad abierta que nos recuerda los movimientos del 2011 en las plazas y espacios abiertos a todo tipo de gente. La propuesta de Calaca sugiere que hay que borrar las fronteras.

En cuanto a la Rotonda Teatro, fundado en 2009, se trata de una compañía también dirigida por tres mujeres, María del Mar Taulés, María Ruiz-Larra y Raquel Rives. Sus puestas en escena se nutren del absurdo, la tragicomedia, el clown y la música en directo. La Rata Britta, por ejemplo, es una pieza de teatro infantil de clown y marionetas que dura 40 minutos. Suelen ser obras cortas destinadas a un público joven. La música va más allá de las palabras: plasma la emoción y, a través del silencio, las palabras. Representa lo universal. El teatro no descansa solo sobre palabras: la comunicación está también basada en lo visual, lo cual facilita la expresión en otros idiomas. El bilingüismo, el papel de la música, permiten rebasar los límites de la lengua. La palabra "rotonda" designa una plaza circular en un cruce entre calles que a menudo tiene un monumento en el centro. Se trata, como en el caso de Calaca, de un espacio abierto y circular que remite al teatro antiguo y se opone al espacio cerrado. La Rotonda Teatro mezcla números de payaso con marionetas, subvirtiendo así las fronteras de género. La obra Cuarteto para piano es un buen ejemplo de ello: pasa en una habitación con goteras. Hay cuatro personajes: tres payasos y un compositor. La música desempeña un papel central. Estamos en lo trágicogrotesco, ya que las lluvias torrenciales provocan inundaciones. Asistimos a intentos de suicidio, pero lo trágico se ve trascendido gracias a la risa. Esta veta tragicogrotesca está también presente en La Siempre Viva, una pieza cómica que ironiza sobre la muerte. Pasa durante un velatorio.

Otras obras como La vie en rose podrían calificarse de feministas. La historia parte de una anécdota: una compañera de piso vuelve a su tierra olvidándose unos zapatos de tacón de veinte centímetros. Los veinte centímetros cambian la vida de la otra compañera. El tacón simboliza la alienación de las mujeres, víctimas voluntarias e inconscientes de la moda. Llevar tacones (o no llevarlos) transforma nuestra forma de ver el mundo: los tacones representan también lo femenino.

Estas obras, breves y actuales, con una escenografía simple, reflejan problemas sociales muy actuales con una estética singular. La espacialidad del exilio es otro espacio, ajeno a las coordenadas espacio-temporales [Cassin 2013].

\section{Conclusión}

La crisis económica que tan duramente han vivido muchos españoles ha tenido también consecuencias en los escenarios, dentro y fuera de España, liberando energías y generando creatividad. Nada de ello hubiera sido posible sin la existencia de un teatro comprometido anterior en el que estos jóvenes creadores se inspiraron. 
Las crisis suelen acompañarse de una reformulación de las relaciones sociales que plasman estas obras. No estamos pues ante el "fin del arte", sino ante la finalización de un determinado tipo de arte, la del "teatro de la representación" y del "teatro de la presentación" [Dubatti 2007: 49].

De la crisis catalana también ha surgido la obra En procès, sobre los acontecimientos del 1ro de octubre. Se trata de una lectura dramatizada, representada los 12 y 19 de febrero de 2018. La referencia estética de los once autores es el "teatro de emergencia". Pero esto sería ya el tema de otro trabajo.

\section{Bibliografía}

Albaladejo, T. (2011): “Sobre la literatura ectópica”, en Adrian Bieniec, Szilvia Lengl, Sandrine Okou, Natalia Shchyhlebska (eds.), Rem tene, verba sequentur! Gelebte Interkulturalität. Festsschrift zum 65. Geburstag des Wissenschaftlers und Dichters Carmine/ Gino Chiellino, Dresden, Thelem: 141-153.

Arendt, H. (2000): El orgullo de pensar, Madrid, Editorial Gedisa.

Augé, M. (1994): Pour une anthropologie des mondes contemporains, París, Editions Auger.

- (2000): Los no lugares. Espacios del anonimato. Una antropología de la sobremodernidad, Barcelona, Gedisa Editores.

Bauman, Z. (1999): Modernidad líquida, Buenos Aires, Fondo de Cultura Económica.

Belmont, N. (1999): Poétique du conte, essai sur le conte de tradition orale, París, Gallimard.

Boal, A. (2009): Teatro del oprimido, Barcelona, Alba.

Cassin, B. (2013): La nostalgie: quand donc est-on chez soi ? Ulysse, Enée, Arendt, París, Autrement.

Dubatti, J. (2007): Filosofia del Teatro I: Convivio, Experiencia, Subjetividad, Buenos Aires, Atuel.

García Canclini, N. (1995): "De las identidades en una época postnacionalista", Cuadernos de Marcha, 101: 17-21.

Habermas, J. (1993): L'espace public, trad. Marc de Launay, París, Payot.

Klein, N. (2008): La stratégie du choc, Toronto, Actes Sud/Arléac.

López Mozo, J. (1976): Teatro de barrio, teatro campesino, Bilbao, Zero.

Los Goliardos (1969): "Hacia el teatro independiente", Primer Acto, 104: 9-13.

Mondzain, M.J. (2002): L'assemblée théâtrale, París, Editions de l'Amandier.

Muschietti, D. (1986): "La producción de sentido en el discurso poético", Filología, XXI, 2: 11-30.

Nancy, J.L. (1986): La communauté désoeuvrée, París, Bourgois, 1986.

Pavis, P. (2014): Dictionnaire de la performance et du théâtre contemporain, París, Colin.

Quirós, R. (2015): "El teatro debe responsabilizarse de la memoria histórica", Raul Quiros Molina, Recurso web <http://raulquirosmolina.es/2018/09/20/el-teatro-debe-responsabilizarse-por-la-memoria-historicas, Fecha de consulta: 30 de enero de 2019.

Sirera, J. L., (2010): "Zero responsables", Yorick, Librería Yorick, Recurso web <http:// www.libreriayorick.com/teatro/textos/8763-zero-responsables.html>, Fecha de consulta: 30 de enero de 2019.

Viñals, C. (2017): "El Pan y la Sal de Raúl Quirós: de la realidad al pie de la letra a una realidad fantomática“, en José Romera Castillo (ed.), El teatro como documento artístico, histórico y cultural en los inicios del siglo XXI, Madrid, Verbum. 
Walter, B. (2009): "Construire un patrimoine et «nourrir la mémoire»", en Nieres-Chevrel, Isabelle (ed.), Introduction à la littérature de jeunesse, París, Didier Jeunesse, 197-214.

Weiss, P. (1968): "Notes sur le théatre documentaire" en Discours sur la génèse et le déroulement de la très longue guerre de libération du Vietnam illustrant la nécessité de la lutte armée des opprimés contre la volonté des Etats Unis d'Amérique d'anéantir les fondements de la révolution, París, Seuil.

Wieviorka, A. (1998): L'ère du témoin, París, Plon. 